\title{
A Psicologia a Serviço do Outro: Ética e Cidadania na Prática Psicológica'
}

Psychology for the other: Ethics and citizenship in the psychological practice

Resumo:Este artigo propõe uma visão da ética da prática psicológica a partir da Filosofia Social de Emmanuel Lévinas. Para isso, retoma a dispersão do saber psicológico, as características da atuação profissional do psicólogo e a discussão sobre cidadania e qualidade de vida.

Palavras-chave: Ética, cidadania, Psicologia, alteridade.

Abstract:This paper proposes an ethical view of the psychological practice in the perspective of Emmanuel Lévinas's Social Philosophy. It deals with the dispersion of the psychological knowledge, the professional characteristics of the psychologist and the discussion about citizenship and life quality.

Key words: Ethics, citizenship, Psychology, alterity.

\section{José Célio Freire}

Doutor em Psicologia pela Universidade de São Paulo. Professoradjunto do

Departamento de Psicologia da Universidade Federal do Ceará, onde leciona a disciplina Ética Profissional no Curso de Graduação em

Psicologia e Ética e Psicologia no Mestrado em Psicologia.

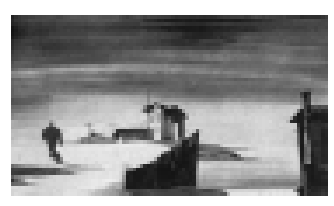

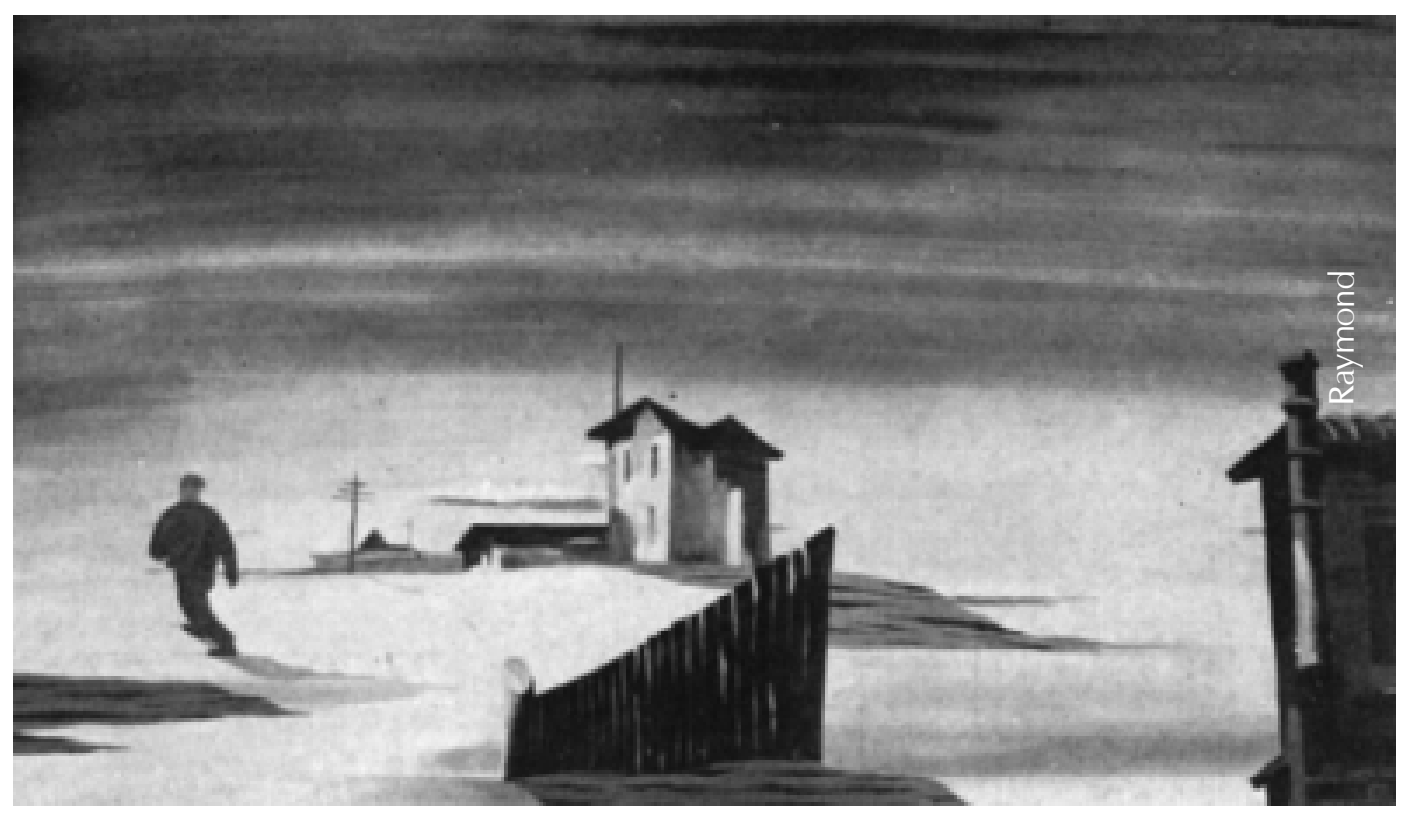

A discussão que pretendemos desenvolver tomará um a um os termos que aparecem no título acima. Tratemos do primeiro deles. O que é para nós a Psicologia? Na forma como se entende normalmente, a Psicologia se propõe a ser um estudo científico do comportamento humano (e animal, para alguns) que se situaria a meio caminho entre o conhecimento biológico e o conhecimento dos processos sociais. Haveria uma unidade de base nessa ontologia regional e as várias teorias se integrariam em um corpo epistêmico comum. Nada mais falso, a nosso ver, que essa idéia unitária da Psicologia.

Hoje compreendemos, diferentemente de Penna (1997), as psicologias no plural como distintas formas de tratar a subjetividade e que, ao fazê-lo, por sua vez, constroem diferentes subjetividades. Ao fato de que não encontramos um objeto uno de estudo para a Psicologia nem um método único de investigação, soma-se a constatação de que produzimos com os nossos discursos sujeitos diferenciados. Assim, enquanto dispositivo constitutivo de subjetividade, cada abordagem psicológica cria seu próprio sujeito-objeto.

Isso por si só nos fala de uma dimensão ética da teoria e da prática psicológicas, no sentido em que a uma determinada compreensão do humano atrela-se a própria fenomenalidade do sujeito. $\mathrm{Ou}$ seja, se cada abordagem, escola ou sistema psicológico cria seu próprio objeto de estudo à sua imagem e semelhança, devem-se levar em conta as diferenças de uma para a outra, respeitando-as enquanto alteridade de discurso. Figueiredo (1995) nos alertara sobre a possibilidade de as várias psicologias serem vistas como "dispositivos éticos de constituição de sujetividades". 
Por seu turno, a cada teorização psicológica corresponde uma intervenção prática específica, seja porque essa intervenção se constitui na mera aplicação de uma teoria, seja porque muitas teorias nasceram de uma prática específica (como a maior parte das teorias de personalidade, que surgiram da clínica psicológica, psiquiátrica ou psicanalítica). Ora, é indubitável também a dimensão ética dessas práticas (Freire, 2002), tendo em vista que essa dimensão diz respeito ao sentido, ao juízo e às conseqüências de comportamentos de uns que afetam a outros.

Mas onde ocorrem tais práticas psicológicas? O que vêm a ser os serviços de psicologia? Eis o segundo termo a tratar. São modelos de atuação psicológica, vinculados a determinadas escolas de pensamento psicológico, que oferecem práticas psicológicas determinadas à população ou, melhor dizendo, aos seus clientes (quer sejam indivíduos, grupos, instituições, organizações ou comunidades). Aliada à dimensão ética inerente aos discursos e práticas psicológicas, tratadas mais acima, está a própria conduta profissional dos psicólogos. Esta, por sua vez, se orienta pelos preceitos estabelecidos no "Código de Ética dos Psicólogos", que a nosso ver nada mais é que um código de postura profissional, acordado pelos próprios psicólogos, através de seu órgão orientador, regulador e, por que não dizer, controlador, que é o Conselho Federal de Psicologia, e dos conselhos regionais que àquele estão vinculados hierarquicamente.

Temos, então, duas evidências. A primeira, de que a toda prática psicológica subjaz um modelo ético específico sujeito às injunções da própria teorização a que se coaduna; a segunda, de que uma "ética" particular - a ética do trabalho psicológico - se coloca no lugar de rectora de toda e qualquer atuação profissional. Aqui e ali podemos vislumbrar conflitos na relação entre essas duas orientações éticas. Tomemos, a título de exemplo, a intrincada situação constituída no setting psicoterápico quando o cliente, ou paciente (ao gosto de cada abordagem), comunica ou mesmo atua perante o profissional uma tentativa de suicídio. Segundo o Código de Ética, dá-se a possibilidade de o psicólogo, por "imperativo de consciência", quebrar o sigilo ético para que outrem auxilie o indivíduo ou que ele mesmo o socorra de alguma forma. Tal atuação do psicoterapeuta, no caso, implicaria um erro técnico em algumas abordagens, uma quebra da confiança depositada pelo cliente na relação terapêutica, em uma outra perspectiva, ou mesmo uma conduta normal para um terceiro grupo de práticas.

Isso nos mostra como é difícil e arriscado pensar a questão ética das psicologias de uma forma unitária e totalizadora. Para que possamos nos dedicar a essa discussão com mais propriedade, no entanto, faz-se necessária uma incursão pelo próprio terreno da Ética enquanto disciplina filosófica, ou mais ainda, enquanto filosofia primeira, como o queria Emmanuel Lévinas (1988). Temos agora o terceiro termo de nossa oração: a Ética. Lévinas, o filósofo da alteridade radical, que entendia a Ética como antecedendo a Ontologia, coloca-nos a visitação do Outro como instauração da subjetividade, primeiro pela separação de Mim em relação ao Outro, depois pela substituição de Mim pelo Outro. Isso quer dizer que se faz necessária uma ida do eu na direção de sua exterioridade e uma implicação do eu pela vinda do Outro que exige uma responsabilidade irrecusável. O outro instaura a possibilidade do eu, e este, por sua vez, se faz necessário para a sujeição ao Outro. Há uma alteridade radical que não pode ser negada ou denegada e que me intima a assumir uma responsabilidade absoluta para com todos os outros. Essa é a dimensão ética por excelência, a do estar a serviço de Outrem, por ele e para ele. Como defenderemos mais adiante, os serviços de Psicologia devem se constituir como modos de estar a serviço do Outro.

Lévinas dizia mais: o lugar que ocupo é usurpação do lugar do Outro; o Outro me fala através da miséria e da nudez de seu Rosto, na viúva, no miserável, no estrangeiro e no órfão; o Outro me obseda, me toma por refém e para com ele tenho uma dívida irresgatável, embora nunca assumida, e ainda mais, com a entrada do terceiro homem (e com ele toda a humanidade) dá-se a necessidade da justiça.

O que isso tem a nos dizer diretamente? Em que uma ética da alteridade radical poderia nos ajudar em termos de uma teorização psicológica ou, o que nos fala mais de perto neste momento, no âmbito dos serviços de psicologia? A questão que podemos nos fazer é: há um lugar para o outro nessas práticas? Tentemos analisar com mais cuidado tal questionamento.

Aquele que procura o serviço de psicologia é um outro em relação ao profissional, em primeiro lugar. Esse cliente, por sua vez, detém um outro em si mesmo, mas também interage com outros específicos em sua família, em seu trabalho, na vida em geral. E, não podemos nos esquecer, foi constituído enquanto subjetividade a partir de um Outro (bem como o profissional ele mesmo). A alteridade está presente de variadas formas nessa relação possível entre o profissional que se oferece e o cliente que o procura.

Tentemos ser mais precisos. O profissional precisa estar consciente do quanto o outro - o cliente, no
1 Originalmente este texto foi utilizado na palestra "Ética e Cidadania nos Serviços de Psicologia", proferida no 20 . pré-Congresso Fortaleza ao IV Congresso Regional de Psicologia, realizado em 21 de abril de 2001, pelo Conselho Regional de Psicologia - 11a. Região, na Casa José de Alencar; em Fortaleza. 
caso -, em sua diferença e exigência, o afirma e confirma. É preciso dispor a escuta para esse outro de forma a poder responder a ele, ao seu sofrimento (nudez e miséria em Lévinas). Essa resposta é responsabilidade: responsabilidade pelo outro, pelo seu sofrimento, por sua angústia. Estar a serviço do outro, portanto, é o que se espera de quem trabalha em um "serviço de psicologia". Oferecer um lugar para o outro - lugar este que desde sempre já seria dele -, abrindo portas e janelas para sua visitação, oferecendo o melhor cômodo e a melhor comida, garantindo-lhe um espaço de habitabilidade, ou seja, um ethos, uma morada confiada e serena onde ele possa renovarse para retomar suas dores no mundo. Essa imagem da Ética enquanto habitação (Heidegger e Lévinas), que diz respeito à casa que cada um de nós precisa erguer para si mesmo no mundo, se presta também à analogia com o serviço de psicologia. Ele deve, portanto, oferecer minimamente essa serenidade, mas sem que se transforme em uma falsa segurança que impede o cliente de ver-se, em sua finitude, habitando a tragicidade do mundo. Morada temporária, eu diria, enquanto o cliente (re)constrói sua própria habitação. Hospitalidade oferecida ao habitante de um mundo inóspito.

\section{Oferecer um lugar para o outro - lugar este que desde semprejá seria dele \\ -, abrindo portas e janelas para sua visitação, oferecendo o melhor cômodo e a melhor comida, garantindo-Ihe um espaço de \\ habitabilidade, ou seja, um ethos, uma morada confiada $e$ serena onde ele possa renovar-se para retomar suas} dores no mundo.

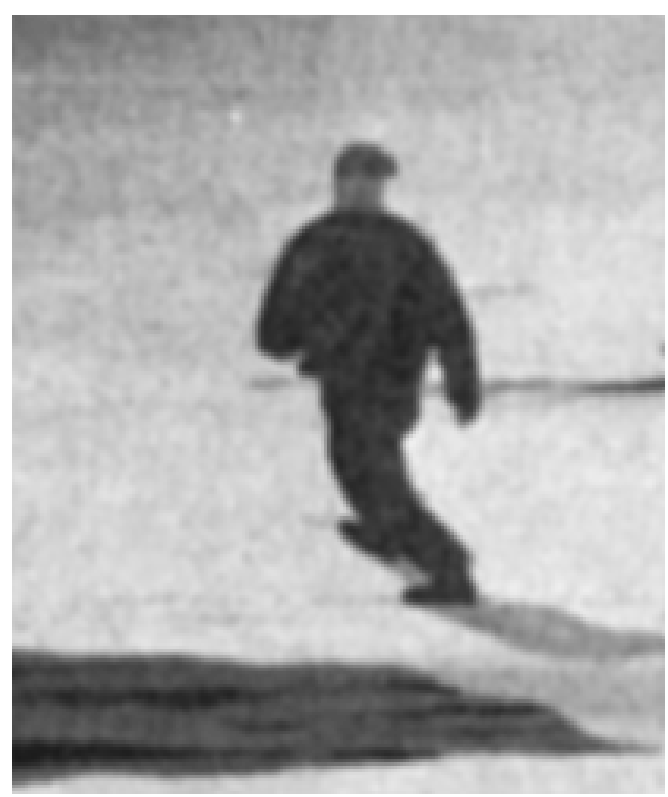

Isso tem a ver, de fato, com a busca de qualidade de vida. Com a necessidade de se estar bem, de gozar "uma vida boa, com e para os outros, em instituições justas" (Ricoeur, 1996). Logo, se aproxima da questão da justiça e da justiça social, mais especificamente. Essa qualidade de vida seria uma dimensão da cidadania, questão dos direitos democráticos. Chegamos ao quarto termo - a cidadania. Ser cidadão, portanto, significa ter o direito de escolher seus representantes no espaço

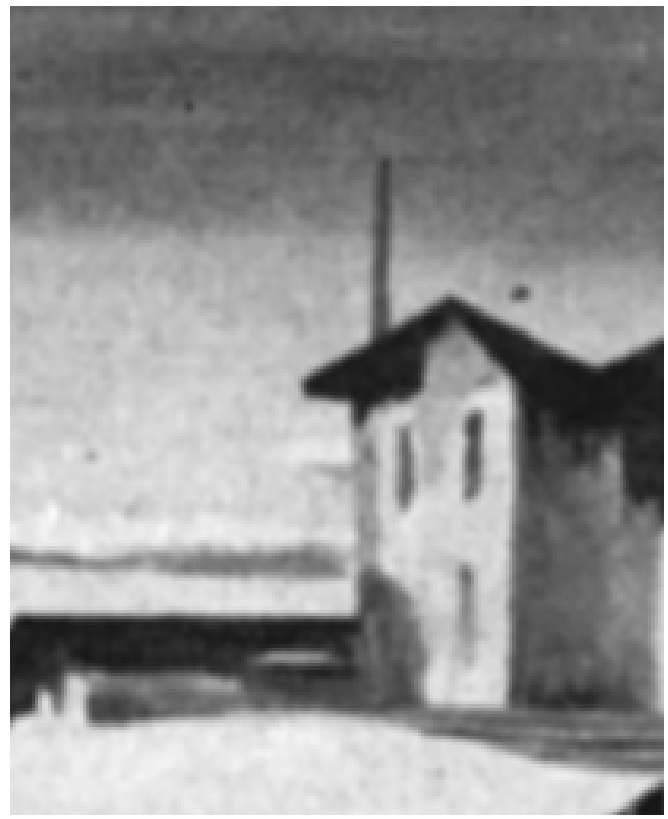

público e fazer valer seus reclamos, mas também significa buscar uma "vida boa" para si e para os outros, e isso implica fazer com que a dimensão da diferença, da criatividade, da produção cultural, possa emergir de cada um - aquilo que Rolnik (1994) denominou de "homem da ética", em oposição ao homem da moral, dos princípios, valores e regras estabelecidos. Este seria necessário, mas não suficiente para aquilo que chamamos de "qualidade de vida".

No atendimento psicológico, significa propiciar condições para que irrompa na pessoa sua própria diferença, seu outro, seu estranho. Disso as psicologias não têm se ocupado muito, preocupadas que estão em reafirmar a identidade de um eu indivisível e autoconsciente. Significa, também, possibilitar o encontro da pessoa com os outros e suas diferenças, com o estrangeiro, com a exterioridade que exige a produção de diferenças.

Temos, assim, um longo caminho a percorrer. Rever nossas teorizações, para ali encontrarmos a impertinência do outro. Renovar nossas práticas, para oferecer condições para a irrupção desse outro nas falas e nos gestos de nossos clientes, pacientes, outros de nós mesmos.

É assim que, em nossa forma de ver, é possível falar-se de Ética e de democracia nos serviços de psicologia. Estar a serviço do outro que nos procura para poder assisti-lo em seu devir-outro e escutar sua alteridade, principalmente naquilo que o fará buscar qualidade de vida para si e para os outros. Quando o outro nos procura, nada melhor que a resposta (originariamente dada à visitação do Outro, em Lévinas) "eis-me aqui". 
José Célio Freire

Av. da Universidade 2762-Campus do Benfica 60.020-180- Fortaleza - CE homepage:www.pospsi.ufc.br E-mail:jcfreire@ufc.br

FIGUEIREDO, Luis Cláudio. Revisitando as Psicologias: da Epistemologia à Ética nas Práticas e Discursos Psicológicos. São Paulo: EDUC; Petrópolis: Vozes, 1995.

FREIRE, José Célio. As Psicologias na Modernidade Tardia: o Lugar Vacante do Outro. Psicologia USP, 12(2), 2002.

LÉVINAS, Emmanuel. Totalidade e Infinito. Lisboa: Ed.70, 1988 (originalmente publicado em 1961).

PENNA, Antônio Gomes. Repensando a Psicologia. Rio de Janeiro: Imago, 1997.

RICOEUR, Paul. Soi-même Comme un Autre. Paris: Éditions du Seuil, 1996. (originalmente publicado em 1990).

ROLNIK, Suely. Cidadania e Alteridade: o Psicólogo, o Homem da Ética e a Reinvenção da Democracia. In: Spink, Mary Jane Paris(org.). A Cidadania em Construção: uma Reflexão Transdisciplinar. São Paulo: Cortez, 1994. 